\title{
Socioeconomic Status and Number of Children Among Korean Women: The Healthy Twin Study
}

\author{
Jinseob Kim, Joohon Sung \\ Preventive Medicine Program, Graduate School of Public Health, Seoul National University, Seoul, Korea
}

Objectives: This study aimed to evaluate whether the birth rate is associated with socioeconomic status in the women of the Republic of Korea, where the birth rate is rapidly decreasing.

Methods: This study included 732 females from the Healthy Twin Study, a family-twin cohort. The participants were classified into 3 socioeconomic groups according to their average income, education, and occupation. The association between socioeconomic status and number of children was assessed using gamma regression analysis with a generalized linear mixed model, adjusting for the age group, smoking/alcohol status, and family relationships.

Results: The group with the highest education level had significantly fewer children compared with the group with the lowest education level $(p=0.004)$. However, no significant associations were found according to household income level. The non-manual labor group had significantly fewer children compared with those working as homemakers $(p=0.008)$.

Conclusions: This study aimed to explain the causal relationship between socioeconomic status and number of children. Associations between some socioeconomic status and number of children were found in Korea.

Key words: Fertility, Family, Social class

\section{INTRODUCTION}

The low birthrate in the Republic of Korea (hereafter, Korea) has come to the fore as one of the most important social problems, yet effective measures for dealing with this problem have not been developed. Since 2001, when Korea joined the lowest-low fertility countries with a total fertility rate of 1.30 , the low birthrate problem has remained unresolved, with Ko-

Received: July 2, 2012 Accepted: December 28, 2012

Corresponding author: Joohon Sung, MD, PhD

1 Gwanak-ro, Gwanak-gu, Seoul 151-742, Korea

Tel: +82-2-880-2828, Fax: +82-2-762-9105

E-mail: jsung@snu.ac.kr

This is an Open Access article distributed under the terms of the Creative Commons Attribution Non-Commercial License (http://creativecommons.org/licenses/by$\mathrm{nc} / 3.0 /$ ) which permits unrestricted non-commercial use, distribution, and reproduction in any medium, provided the original work is properly cited. rea recording the second lowest birthrate in the world in 2009, at 1.15, and 1.22 in 2010 [1]. The low birthrate, linked to a reduction in the labor supply and an aging population, has led to an aging industrial workforce and a reduction in labor productivity. This reduces the national revenue while increasing annual expenditures and, consequently, causes a worsening of capital accounts and a slowdown in economic growth. According to the Korea Labor Institute's Medium- and Long-term Manpower Supply and Demand Forecast: 2005-2020, Korea will face a labor supply shortage of 630000 workers in 2015, and 1520000 by 2020. This is without question one of Korea's greatest problems [2]. Therefore, it is very important to understand the causes of the low birthrate phenomenon in order to respond with policy measures. In particular, understanding the socioeconomic factors influencing the low birthrate will greatly aid in national policymaking in the future.

Research on low birthrates and the influence of socioeco- 
nomic levels on birthrates goes back to the 1960's, when Becker et al. [3] proposed the Quantity-Quality model, in which the number of children decreases with the increase in a household's income, following the supposition that income elasticity for quality of children is greater than income elasticity for quantity of children, and this created a theoretical foundation for this area of study. Heckman and Willis [4] proposed the lifetime utility model, which accounted for the period of childbirth through the comparison of marginal utility and marginal cost. If wages were to increase with time, which would mean that childbirth/childcare expenses would increase, women would give birth at a younger age. On the other hand, if there were little or no increase in wages, childbirth would be delayed. Consequentially, they claimed that highly educated women with a higher income tend to delay childbirth. Many studies have been carried out in order to verify this theory [5-8].

Studies dealing with the socioeconomic factors influencing fertility have mostly looked at the effect of economic activities such as jobs, as well as income and education levels. Among these factors, the increase in the education level of women led to an increase in participation in economic activity and emerged as a significant influence on the decline of fertility. Some studies show a relation between a rise in income levels and fertility while others find no relation. There are studies showing the number of children is lower in cases where women are engaged in economic activity than when they are not [9-12].

Domestically, research gradually began to be undertaken in the first decade of the new millennium, when the problem of the low birthrate grew serious. Kwon and Kim [13] reported that the birthrate of the middle-class was lower than that of those with high or low incomes. Those with very high incomes had relatively little concern about child rearing, while the choices of those with very low incomes were explained as a type of gambling to improve their socioeconomic status. Lee [12] found that the greater the job experience the young and highly educated have, the lower the marriage rate. While there are other claims besides that, the truth is that much about the factors that influence low birthrates still remains unelucidated.

Accordingly, in this study we attempt to evaluate the relationship of socioeconomic determinants, such as women's occupation, educational level, and average income, to the number of children women have as direct indicators of their birthrate based on data from a Korean family-twin cohort in the (Healthy Twin Study, Korea) [14]. On the one hand, aside from socioeconomic status, it is known that a history of smoking and drinking by women reduces pregnancy rates and influences fertility. These issues need to be taken into consideration and these behaviors should be examined as well [15-17]. Using data gathered from families and twins, rather than individuals, we were able to conduct a study that controls for genetic factors and environmental factors common to a family that influence fertility, allowing us to understand the influence of precise socioeconomic levels.

\section{METHODS}

\section{Research Subject}

The Healthy Twin Study, Korea, used in this paper, is a cohort that began in May of 2005 as one part of a government-sponsored genomic cohort project. This paper uses data gathered until December 2009. This cohort $(n=2860)$ consisted of same-sex twins over 30 and their immediate families and was formed through the Samsung Seoul Hospital and Inje University Busan Paik Hospital using advertisements put out by government institutions and participating hospitals. A detailed account of the study's protocol and objectives can be found in another paper [18]. Two-thousand eight-hundred sixty individuals (twins and family members) were the subjects of this study. Among these, 1262 women were selected, excluding the male subjects and those with missing values. Generally, when conducting a study on women of childbearing age, many times, ages 15 to 44 are examined. In some instances, the age limit is set somewhere around 40 . In this study, including subjects aged 44 and above would have included 578 women. This was about 20\% fewer subjects than if the 738 women aged 40 and above had been chosen. Therefore, finally, we decided to use the data on the larger group of women aged 40 and above for our analysis [19].

\section{Measurements}

The number of children born to the women was used as a dependent variable, expressed as non-negative integers $(0,1$, $2,3 \ldots$... Among the female reproductive research data of The Healthy Twin Study, the total number of babies born to subjects was examined, and the answer was used as the dependent variable. Additional female reproductive data included the subject's husband's occupation, age when first married and of menarche, parity, abortion history, age at the birth of the first and last children, and contraception use. 
The women subjects' education level, average monthly household income, occupation, smoking history, drinking history, and age group were used as explanatory variables for fertility. Education levels were classified into three categories: no high school degree, high school graduation, and junior college and above. The average monthly household income was classified into three categories: under under 1.5 million, 1.5 to 3 million, and over 3 million Korean won ( $\forall, 1$ million won is about 1000 US dollar), working under the premise that, as it is impossible to precisely know past income, there would not be such a large difference between the present income and past income. Assuming that the subject's current occupation could not reflect their job status at the time of childbirth, we used the subject's representative job, the one which they had worked for the longest period of time, as a standard. We divided occupation into three categories: non-manual workers (administrators, professionals, engineers or semi-professionals, white-color workers, service-related workers or sales-related workers), manual workers (skilled agricultural and fishery workers, craft and related workers, plant and machine operators and assemblers, unskilled laborers), and homemakers. Where there was a missing value for the subject's primary occupation, the current occupation was used instead. Smoking and drinking history was divided into one of three categories: current consumer of cigarettes and alcohol, past consumer, and never consumer. Age was divided into three categories: 40 's, 50 's, and 60 and above.

\section{Statistical Analysis}

Initially we looked for descriptive statistics for the familytwin structure, independent variables, and dependent variables of the research subjects. Next, we calculated descriptive statistics for the number of children for each independent variable individually. We conducted a univariate analysis in a generalized linear mixed model (GLMM) to determine if the difference was significant [20]. In addition, before developing an explanatory model, we calculated the intraclass correlation coefficient (ICC) in order to evaluate how much influence the twin effect and family effect had in the distribution of the total number of children. Finally, when we included all of these independent variables in the model, we estimated the effect on the number of children and used a regression analysis with a final GLMM, adjusted for the genetics and shared environmental effects of identical twins or families. Meanwhile, the thing that should be considered regarding methodology when at- tempting to analyze the determinants of Korea's present birthrate of 1 or 2 children is finding the appropriate distribution that accounts for the number of children. The number of children expressed as a non-negative integer frequently assumes a compliance with a Poisson distribution, but a Poisson distribution has an equal variance and mean, so when the variance and mean do not correspond, we are unable to obtain an unbiased estimator. In cases of over-dispersion, when the variance is often larger than the mean, negative-binomial distribution is used. Conversely, when the mean is bigger than the variance, gamma distribution is used. The number of children is known to often follow gamma distribution with a larger mean than variance $[21,22]$. Accordingly, in this study, depending on the form of the data, by conducting analysis supposing either a Poisson distribution or gamma distribution, we carried out a more precise evaluation of the relationships among variables. Once confirming that the data distribution suited a gamma distribution more than a Poisson distribution, we applied dependent variables only when their distribution was a gamma distribution in the GLMM.

\section{Gamma regression analysis}

Generally, it is thought that with the distribution of the number of children, since the mean is often larger than the variance, the gamma distribution will be the probability density function. When a dependent variable is Poisson distributed or Gamma distributed and is used in a regression analysis, the link function is taken as a logarithm. Accordingly, the following regression analysis model was used in this study [23].

$$
\begin{aligned}
& \log \left(\mu_{i j}\right)=\beta_{0}+\text { Education }_{i j}+\text { Income leve }_{i j}+\text { Occupation leve }_{i j}+\text { Age } \\
& \text { group }_{i j}+\text { Alcohol }_{i j}+\text { Smoke }_{i j}+M Z \text { twin }_{i}+e_{i j} \text { (eqation 1) } \\
& \text { (i: } M Z \text { twin category, }{ }_{j}=\text { individual, } \mu_{i j}=E\left(Y_{i j}\right), Y_{i j} \text { : number } \\
& \text { of children, MT twin: random effect, e eij: error) }
\end{aligned}
$$

\section{Generalized linear mixed model}

The GLMM is a regression analysis used to study random effects in the analysis of dependent variables that do not conform to a normal distribution [23]. Because the subjects of this study are families, they are not independent but inter-related, a feature that requires revision using models such as a random effect model. As the distribution of the number of children does not conform to a normal distribution, it is appropriate to use a GLMM [20]. Using a GLMM, we can estimate the extent of genetic factors and unmeasured shared environment 
through identical twins or families. Indeed, we can estimate the percentage of the variance due to family structure out of the total variance and the variance due to twins out of the total variance. Meanwhile, for the sake of model simplification, we only used one of two family structures. For example, if the variance due to family and the variance between twins was very small within the variance of the total number of children, we were able to effectively simplify the statistical model by only including one of the two in an explanatory model. After we confirmed that the family effect was relatively very small, we studied the twin-effect as a random effect. This assumes that identical twins have, among themselves, the same degree of correlation, while there is no correlation for non-twins. By

Table 1. General characteristics of the subjects

\begin{tabular}{|c|c|}
\hline Variable & $\mathrm{n}=732$ \\
\hline \multicolumn{2}{|l|}{ Age (y) } \\
\hline $40-49$ & $340(46.5)$ \\
\hline $50-59$ & $218(29.8)$ \\
\hline$\geq 60$ & $174(23.8)$ \\
\hline Mean \pm SD & $52.1 \pm 8.9$ \\
\hline \multicolumn{2}{|l|}{ Educational } \\
\hline Middle school or less & $340(46.5)$ \\
\hline High school & $243(33.2)$ \\
\hline College or more & 149 (20.4) \\
\hline \multicolumn{2}{|c|}{ Income (Korean won per month) } \\
\hline$<150$ & 239 (32.7) \\
\hline $150-300$ & $268(36.6)$ \\
\hline$>300$ & $225(30.7)$ \\
\hline \multicolumn{2}{|l|}{ Occupation } \\
\hline Manual & $300(41.0)$ \\
\hline Non-manual & $141(19.3)$ \\
\hline None & $271(37.0)$ \\
\hline Missing value & $20(2.7)$ \\
\hline \multicolumn{2}{|l|}{ Smoking } \\
\hline No & 672 (91.8) \\
\hline Past & $15(2.0)$ \\
\hline Current & $39(5.3)$ \\
\hline Missing value & $6(0.01)$ \\
\hline \multicolumn{2}{|l|}{ Alcohol } \\
\hline No & $364(49.7)$ \\
\hline Past & $50(6.8)$ \\
\hline Current & $317(43.3)$ \\
\hline Missing value & $1(0.1)$ \\
\hline \multicolumn{2}{|l|}{ Child number } \\
\hline Mean \pm SD & $2.72 \pm 1.3$ \\
\hline
\end{tabular}

Values are presented as number (\%) or mean \pm SD. positing this kind of model, we are able to take into consideration the shared environment and the hereditary congruity of identical twins. When family structure was set as the model, having found that the variance accounting for family structure was quite a minor portion of the total variance, we can definitely say that we consider hereditary congruity to account for a large portion of the total variance. Through the GLMM, we can determine to what degree hereditary factors account for variance in the total number of children. Taking this into consideration, we can determine the degree to which socioeconomic levels have an effect. In this study, after first finding the socioeconomic level effect that considers identical twin structure, in order to know the influence identical twins had on the number of children, we looked only at twins and families and did not include anything as independent variables. Then we looked for intraclass correlation coefficients of a variance that accounts for the corresponding structures. Then we found a proportion of variance that accounts for twins within a regression analysis adjusted for independent variables and compared it with the proportion of variance when nothing was included as an independent variable. Through this procedure, even excluding socioeconomic levels, we were able to determine the degree to which the twin effect remained unaccounted for, allowing us to predict how much of it is hereditary. All analyses were conducted using SAS version 9.2 (SAS Institute Inc., Cary, NC, USA) and R version 2.14.1 (University of Auckland, Auckland, New Zealand).

\section{RESULTS}

\section{Research Subjects' General Characteristics}

In Table 1 we proposed descriptive statistics about the general characteristics of the group that we analyzed. Out of 732

Table 2. Familial structures of the subjects

\begin{tabular}{|c|c|c|c|c|c|c|}
\hline \multirow{2}{*}{$\begin{array}{l}\text { No. of } \\
\text { family } \\
\text { member }\end{array}$} & \multicolumn{2}{|c|}{ Family number } & \multicolumn{3}{|c|}{ Family structure } & \multirow{2}{*}{$\begin{array}{l}\text { No. of } \\
\text { person }\end{array}$} \\
\hline & All & $\begin{array}{c}\text { Include } \\
\text { MZ }\end{array}$ & $\begin{array}{c}\text { 1st } \\
\text { degree }\end{array}$ & $\begin{array}{c}\text { 2nd } \\
\text { degree }\end{array}$ & $\begin{array}{c}\text { 3rd } \\
\text { degree }\end{array}$ & \\
\hline 1 & 241 & 0 & 241 & 0 & 0 & 241 \\
\hline 2 & 97 & 45 & 79 & 18 & 0 & 194 \\
\hline 3 & 52 & 27 & 33 & 19 & 0 & 156 \\
\hline 4 & 19 & 12 & 16 & 3 & 0 & 76 \\
\hline 5 & 7 & 5 & 5 & 2 & 0 & 35 \\
\hline 6 & 5 & 4 & 3 & 2 & 0 & 30 \\
\hline All & 421 & 93 & 377 & 44 & 0 & 732 \\
\hline
\end{tabular}

$M Z$, monozygotic twin. 
female subjects, 340 (46.5\%) were under 50 years old, 218 (29.8\%) were ages 50 to 60 , and 174 (23.8\%) were 60 years and above. The mean age was 52.1 and the standard deviation was 8.9 years. Regarding education levels, 340 individuals (46.5\%) had not finished high school, 243 (33.2\%) had a high school education, and 149 (20.4\%) had graduated from junior college or higher. With regard to average monthly household income, 239 individuals (32.7\%) made under $\# 1500$ 000, 268 (36.6\%) earned between $\forall 1500000$ and $\forall 3000$ 000, while $225(30.7 \%)$ earned greater than $\$ 3000000$. There were a total of 421 families and 93 sets of identical twins. 300 (41\%) subjects had manual labor jobs as their primary occupation, 141 (19.3\%) worked in non-manual occupations, and 271 (37\%) were full-time homemakers. Cigarette and alcohol consumption history, categorized as never consumed, former consumers, and current consumers, came to $672(91.8 \%), 15$ (2\%), 39 (5.3\%) and 364 (49.7\%), 50 (6.8\%), and 317 (43.3\%), respectively.

The mean number of children was 2.72 with a standard deviation of 1.3. The distribution of the number of children showed, as expected, to be closer to a gamma distribution than a Poisson distribution, and because the mean was bigger than the variance, we believe there was a need to use a Gamma rather than Poisson distribution.

The families and sets of twins who participated in this study are shown in Table 2 . The distribution of the number of family members included a total of 421 families. The number of families having 1 to 6 family members, was, in order, 241, 97, 52, 19,7 , and 5 . The number of sets of identical twins in families having 1 to 6 family members was, following the same order, 0 , $45,27,12,5$, and 4 , for a total of 93 sets. Forty-four sets of twins were part of two-generation families, while no families consisted of three generations.

\section{Difference in Number of Children for Each Inde- pendent Variable Category}

In order to find the difference in the number of children according to the independent variables, we attempted to compare the mean with each independent variable's category (Table 3). As the educational level and average monthly household income increased, we saw a trend toward a diminishing number of children, and when only a single independent variable was entered into the model, the type 3 fixed effect had a $p$-value of less than 0.001 . For occupation, the economically inactive population had the least number of children, while manual laborers had a higher number, and non-manual laborers even higher $(p<0.001)$. Within different age groups we found that as age increased from 40's to 50 's to 60 's, we saw an increase in the number of children $(p<0.001)$. Regarding smoking and drinking history, the results showed a trend toward a smaller number of children the more current consumers consumed tobacco or alcohol. The $p$-value was 0.099 for tobacco consumption and under 0.001 for alcohol consumption.

\section{Multiple Regression Analysis Using Generalized Linear Mixed Model}

Before conducting a multiple regression analysis, in order to determine the influence of family structure on the total variance, we calculated the proportion of the variance accounted for by family structure as an ICC in a null model that did not include any variables. We determined that the proportion of

Table 3. Differences of child number according independent variables

\begin{tabular}{lcc}
\hline Variable & Mean \pm SD & p-value \\
\hline Education & & $<0.001$ \\
Middle school or less & $3.259 \pm 1.362$ & \\
High school & $2.403 \pm 1.049$ & \\
College or more & $2.013 \pm 0.771$ & $<0.001$ \\
Income (Korean won per month) & & \\
$<150$ & $3.151 \pm 1.409$ & \\
150-300 & $2.552 \pm 1.221$ & \\
$>300$ & $2.467 \pm 1.044$ & \\
Occupation & & \\
Manual & $2.663 \pm 1.258$ & \\
Non-manual & $2.007 \pm 0.77$ & \\
None & $3.166 \pm 1.316$ & \\
Age-group (y) & & \\
40-49 & $2.003 \pm 0.658$ & \\
$50-59$ & $2.688 \pm 1.079$ & \\
$\geq 60$ & $4.167 \pm 1.183$ & \\
Smoking & & \\
None & $2.76 \pm 1.257$ & \\
Past & $2.333 \pm 1.915$ & \\
Current & $2.205 \pm 1.174$ & \\
Alcohol & & \\
None & $2.992 \pm 1.353$ & \\
Past & & \\
Current & & \\
\hline & & \\
\hline & & \\
\hline
\end{tabular}

$p$-values are obtained by generalized linear mixed model using only one variable and monozygotic twin clusters. 
variance of 0.02 based on family structure could not fully account for the number of children (Table 3). The ICC value accounting for identical twins (Table 4) was 0.766 , whereas that for regular families had almost no influence. We discovered that the number of children between identical twins is an im-

Table 4. Variance components according clusters and models

\begin{tabular}{lccc}
\hline Cluster & $\begin{array}{c}\text { Variance } \\
\text { of cluster }\end{array}$ & $\begin{array}{c}\text { Residual } \\
\text { variance }\end{array}$ & $\begin{array}{c}\text { Proportion of variance } \\
\text { explained by cluster }\end{array}$ \\
\hline $\begin{array}{l}\text { Family } \\
\text { Null model }\end{array}$ & 0.004 & 0.198 & 0.02 \\
$\begin{array}{c}\text { MZ twin } \\
\text { Null model }\end{array}$ & 0.152 & 0.047 & 0.766 \\
Full model $^{2}$ & 0.02 & 0.077 & 0.202 \\
\hline
\end{tabular}

$\mathrm{MZ}$, monozygotic twin.

${ }^{1}$ No independent variables.

${ }^{2}$ Contain all independents variables. portant matter for consideration. In comparison, in multiple regression analysis models considering all independent variables, the variance accounting for identical twins decreased by 0.20 . Consequently, in the correlation valuation of socioeconomic levels, by modifying only whether there were identical twins and not considering families, an effective model composition was possible.

We compared the univariate regression analysis and the full model, that is, the multiple linear regression analysis (Table 5). For educational levels, univariate models showed a trend of a decreasing number of children the higher the education level. The full model agreed with the trend of reduced numbers of children with increased education, and only when comparing the very highly educated and those with a middle school education and lower did a significant difference appear (relative risk [RR], 1.196; 95\% confidence interval [Cl], 1.107 to 1.293).

Table 5. Regression analysis on child number using generalized linear mixed model

\begin{tabular}{|c|c|c|c|c|}
\hline Variable & Crude RR $^{1}(95 \% \mathrm{CI})$ & $p$-value (crude RR) & Adjusted RR ${ }^{2}$ (95\% CI) & $p$-value (adjusted RR) \\
\hline Intercept & $2.848(2.750,2.950)$ & $<0.001$ & $2.848(2.750,2.950)$ & $<0.001$ \\
\hline \multicolumn{5}{|l|}{ Education } \\
\hline Middle school or less & $1.557(1.436,1.689)$ & $<0.001$ & $1.196(1.107,1.293)$ & $<0.001$ \\
\hline High school & $1.166(1.073,1.267)$ & 0.002 & $1.061(0.989,1.138)$ & 0.12 \\
\hline College or more & 1 & & 1 & \\
\hline \multicolumn{5}{|c|}{ Income (Korean won per month) } \\
\hline$<150$ & $1.248(1.156,1.347)$ & $<0.001$ & $0.995(0.932,1.062)$ & 0.88 \\
\hline $150-300$ & $1.033(0.963,1.108)$ & 0.37 & $0.95(0.896,1.008)$ & 0.10 \\
\hline$>300$ & 1 & & 1 & \\
\hline \multicolumn{5}{|l|}{ Occupation } \\
\hline Manual & $0.856(0.801,0.916)$ & $<0.001$ & $0.951(0.901,1.004)$ & 0.08 \\
\hline Non-nanual & $0.692(0.639,0.750)$ & $<0.001$ & $0.9(0.837,0.968)$ & 0.008 \\
\hline None & 1 & & 1 & \\
\hline \multicolumn{5}{|l|}{ Age-group (y) } \\
\hline $40-49$ & $0.49(0.461,0.521)$ & $<0.001$ & $0.549(0.512,0.589)$ & $<0.001$ \\
\hline $50-59$ & $0.659(0.617,0.704)$ & $<0.001$ & $0.677(0.634,0.722)$ & $<0.001$ \\
\hline$\geq 60$ & 1 & & 1 & \\
\hline \multicolumn{5}{|l|}{ Smoke } \\
\hline None & $1.2(1.046,1.377)$ & 0.04 & $1.096(0.984,1.219)$ & 0.15 \\
\hline Past & $1.226(0.958,1.569)$ & 0.16 & $0.96(0.783,1.177)$ & 0.71 \\
\hline Current & 1 & & 1 & \\
\hline \multicolumn{5}{|l|}{ Alcohol } \\
\hline None & $1.187(1.114,1.265)$ & $<0.001$ & $1.025(0.974,1.079)$ & 0.35 \\
\hline Past & $1.128(1.009,1.261)$ & 0.04 & $1.055(0.959,1.161)$ & 0.28 \\
\hline Current & 1 & & 1 & \\
\hline
\end{tabular}

$\mathrm{RR}$, relative risk; $\mathrm{Cl}$, confidence interval.

${ }^{1} \mathrm{RR}$ based on univariate analysis.

${ }^{2} \mathrm{RR}$ based on multivariate analysis. 
With regard to the average monthly household income, the univariate model showed a trend toward a lower number of children with increasing income. Compared with high-income families, the group with incomes of under $\forall 1500000$ produced a significantly larger $\mathrm{RR}$ value (RR, 1.248; $95 \% \mathrm{Cl}, 1.156$ to 1.347). Within the full model, the under $W 1500000$ group and the over $\forall 3000000$ group showed a trend toward having a greater number of children compared to the group with the average household income of $\# 1500000$ to $\# 3000000$. There were no statistically significant results from this model. In the case of occupational factors, in the full model, the number of children for non-manual laborers was the smallest, and when compared with full-time homemakers, we were able to obtain a significant $\mathrm{RR}(\mathrm{RR}, 0.9 ; 95 \% \mathrm{Cl}, 0.837$ to 0.968$)$. For the age groups, we were able to obtain results with both univariate analysis as well as the full model showing a significant increase in the number of children for the higher age brackets. No significant difference could be found for tobacco or alcohol consumption history in the full model.

\section{Multiple Regression Analysis Stratified by Age Group}

Having found in both the univariate analysis and multiple regression analysis that age group exerts a large influence on the number of children, we conducted a multiple regression analysis for individual age groups (Table 6). In order to simplify the income level effect, we analyzed the monthly average household income as a binary variable with $¥ 3000000$ as the threshold. We found that the number of children for those in their 40s with a middle school education and lower was, statistically, significantly lower than that of highly educated people in the same age group (RR, $1.128 ; 95 \% \mathrm{Cl}, 1.023$ to 1.243 ). Those 60 and over showed a clear trend toward a decreasing number of children with an increase in education, while we were not able to obtain significant results for the group of those in their 50s. For income levels, we found that within the 40-year-old group, the number of children of the lower income group, those making less than $\forall 3000000$, was significantly lower than that of the higher income group making

Table 6. Regression analysis on child number according age groups

\begin{tabular}{|c|c|c|c|c|c|c|}
\hline \multirow[b]{2}{*}{ Variable } & \multicolumn{2}{|c|}{$40 \leq$ age $\leq 49$} & \multicolumn{2}{|c|}{$50 \leq$ age $\leq 59$} & \multicolumn{2}{|c|}{$60 \leq$ age } \\
\hline & $\begin{array}{l}\text { Adjusted RR }{ }^{1} \\
(95 \% \mathrm{CI})\end{array}$ & $p$-value & $\begin{array}{l}\text { Adjusted RR } \\
(95 \% \mathrm{Cl})\end{array}$ & $p$-value & $\begin{array}{l}\text { Adjusted RR } \\
(95 \% \mathrm{CI})\end{array}$ & p-value \\
\hline Intercept & $1.942(1.676,2.251)$ & $<0.001$ & $2.338(1.725,3.168)$ & $<0.001$ & $3.559(2.617,4.841)$ & $<0.001$ \\
\hline \multicolumn{7}{|l|}{ Education } \\
\hline Middle school or less & $1.128(1.023,1.243)$ & 0.02 & $1.103(0.904,1.344)$ & 0.33 & $1.266(1.112,1.441)$ & $<0.001$ \\
\hline High school & $1.06(0.981,1.147)$ & 0.14 & $0.934(0.769,1.135)$ & 0.49 & $1.151(1.015,1.306)$ & 0.03 \\
\hline College or more & 1 & - & 1 & - & 1 & - \\
\hline \multicolumn{7}{|c|}{ Income (Korean won per month) } \\
\hline$\leq 300$ & $0.93(0.868,0.996)$ & 0.04 & $1.105(0.975,1.251)$ & 0.12 & $0.992(0.884,1.114)$ & 0.89 \\
\hline$>300$ & 1 & - & 1 & - & 1 & - \\
\hline \multicolumn{7}{|l|}{ Occupation } \\
\hline Manual & $0.967(0.891,1.050)$ & 0.42 & $0.916(0.824,1.018)$ & 0.10 & $1(0.911,1.098)$ & 0.10 \\
\hline Non-manual & $0.91(0.833,0.995)$ & 0.04 & $0.831(0.695,0.994)$ & 0.04 & $0.87(0.765,0.988)$ & 0.03 \\
\hline None & 1 & - & 1 & - & 1 & - \\
\hline \multicolumn{7}{|l|}{ Smoke } \\
\hline None & $1.059(0.935,1.199)$ & 0.36 & $1.147(0.901,1.460)$ & 0.26 & $0.965(0.726,1.282)$ & 0.80 \\
\hline Past & $0.851(0.622,1.165)$ & 0.31 & $0.781(0.496,1.231)$ & 0.28 & $1.025(0.705,1.491)$ & 0.90 \\
\hline Current & 1 & - & 1 & - & 1 & - \\
\hline \multicolumn{7}{|l|}{ Alcohol } \\
\hline None & $1.051(0.98,1.127)$ & 0.16 & $0.971(0.874,1.079)$ & 0.58 & $1.004(0.908,1.110)$ & 0.94 \\
\hline Past & $1.161(1.027,1.311)$ & 0.02 & $0.924(0.764,1.116)$ & 0.41 & $1.086(0.835,1.412)$ & 0.54 \\
\hline Current & 1 & - & 1 & - & 1 & - \\
\hline
\end{tabular}

$\mathrm{RR}$, relative risk; $\mathrm{Cl}$, confidence interval.

${ }^{1} \mathrm{RR}$ based on multivariate analysis. 
above $\forall 3000000$ per month (RR, $0.93 ; 95 \% \mathrm{Cl}, 0.868$ to 0.996). We found no significant results for the over 60 group. For occupation, non-manual laborers showed a trend toward fewer children across all age groups, and showed statistically significant results when compared with homemakers. For tobacco and alcohol consumption, we found that in the group of those in their 40 s, past consumers had a significantly higher number of children than current consumers (RR, 1.161; 95\% $\mathrm{Cl}, 1.027$ to 1.311$)$.

\section{DISCUSSION}

\section{Summary of Study Results and Comparison with Previous Studies}

This study's results showed that even when adjusting for influences of other variables, by and large, the higher the subject's level of education, the lower the number of children. This conclusion partially corresponds with the life cycle utility model of Heckman and Willis [4]. Indeed, it supports the hypothesis that the higher a woman's education or income is, the later childbirth occurs and the fewer babies are born. This it true when wages are either not very high or do not appreciate along as time passes, whereas childbirth fees do not significantly increase. Moreover, this also corresponds with the findings of Lee [12] and supports the explanation that as education levels increase, economic activity participation increases, and compatibility between work and family life becomes difficult. Income levels in and of themselves showed a trend toward a diminishing number of children with increased income. After considering other variables, a tendency toward a Ushaped pattern could be seen, but there were no statistically significant results. These results do not correspond with Heckman's life cycle utility model or Becker's Quantity-Quality model [3], and can be seen to correspond more with the Ushaped model proposed by Kwon and Kim [13]. With regard to occupation, in a univariate analysis, the number of children for non-manual laborers was significantly lower than that of other groups, and even after considering other variables, the results showed the number of children for non-manual laborers to be significantly lower than that of full-time homemakers. If we consider that non-manual workers are relatively highly educated, we may say that corresponds to some extent with the educational level results. In the data of this study, there was a trend toward significantly higher education for non-manual workers compared to other groups $(p<0.001)$. Even after tak- ing other variables into consideration, the number of children for non-manual workers was significantly lower compared to that for homemakers. This partially corresponds with studies claiming that women with work experience have a low number of children, and likewise corresponds with the explanation that economic activity participants spend relatively less energy on their families.

If we look at age, regardless of other variables, we confirmed that the number of children sees a pronounced increase with an increase in age. This signifies either a period effect or a cohort effect exerting an influence on the number of children itself. If the former, factors such as the growth in birth control or a change in childbirth-related policy by the government can account for this. If the latter, we can account for it as the childbearing by married women of childbearing age being influenced by when some policies were implemented [12]. The Family Planning Program began in earnest in 1962, launching with the slogan "Let's have few children and bring them up well," and lead to the practice of birth control through education and advertisements and the introduction of a nationwide movement and various contraception methods. In the early 1970's, when the birthrate had had reached its peak, the government adopted the slogan, "Boy or girl, let's have just two children and raise them well," and unfurled a powerful birth control movement, legalized abortion, and introduced various tax exemptions and similar incentives. Since the late 1980's, having reached their target, the birth control policy was relaxed, and, in the mid-90's, the population control policy was abolished. Since 2004, the Presidential Committee on Aging and Future Society was established, a national road-map was created, and the Childbirth Encouragement Policy was implemented. Accordingly, we may say that those in their 50's were influenced by the birth control policy of a relatively forceful government, and can guess that those in their 40's were less influenced by government policies such as birth encouragement and birth control policies. When a stratified analysis was carried out by age group, the education effect for those in their 40s showed a trend similar to the analysis conducted on the entire group of subjects. Notably, those with an income of \#3 000000 and above were found to have a significantly higher number of children. This conclusion corresponds in part with existing domestic research showing an increase in the number of children with an increase in income [19]. Whereas, looking at the lack of a significant income effect for the group in their 50 s and those 60 and above, we can interpret the low 
economic levels of the relatively recent past as being the cause for a low birthrate. On the one hand, this explains the situation for this age group when they were married or had children; on the other hand, it appears as if the present day average monthly household income is not a suitable indicator. When we compared the group of those 60 and above with the other age groups, the "higher education-lower number of children effect" was even more marked. This could be explained by the fact that, in the past, obstacles to higher education were relatively high and education's impact was more significant. We did not obtain any significant results for the group in their 50s, apart from occupation, which was similar to the findings when we analyzed the whole group. In the case of income, while the average monthly household income is most probably not a suitable indicator, as previously mentioned, seeing that education levels were also found to have no significant relation, it appears that the period effect or cohort effect is relatively large. This conclusion corresponds with the assumption that the group in their 50s was most influenced by the government's birth control policies. We believe that the veracity of this assumption can be determined in future studies.

\section{Hereditary Factors Influencing the Number of Children}

By determining that family structure played a very small role in accounting for the number of children, after determining that the effect of the shared environment was also small, using identical twin subjects, we were able to approximately estimate the degree to which hereditary factors influenced the number of children. The percentage comprising identical twins in the total distribution was 0.766 in the null model and 0.202 in full model. This, even after considering a number of variables, signifies the existence of a portion accounted for by identical twins. Accordingly, we may conjecture the existence of hereditary factors that exert an influence on the number of children. Accordingly, though the conclusions of this study are indirect, they can be said to take hereditary factors into consideration. Henceforth, when analyzing factors influencing low birthrate, this study's findings that hereditary factors had a $20 \%$ explanatory power for fertility, even after considering other factors, and that shared environment had a very small influence will serve as important reference data.

\section{Limitations and Future Subjects}

In the Healthy Twin Study data used in this paper, including the identical twin data, it is difficult to represent ordinary women with respect to the giving and taking of help in the childcare process. Apart from that, we also adjusted for socioeconomic levels such as women's educational level and income, as well as occupation only. That we could not account for other socioeconomic levels such as age at the time of marriage, the husband's occupation, educational level, etc., was another limitation. In addition, there was the problem of multi-colinearity between socioeconomic variables. One problem is that it is difficult for the average monthly household income to account for the socioeconomic situation at the time of childbirth. 40- to 45-year-old subjects had the shortest time period between giving birth and the study, so we believe that the average monthly household income for this group represented the income at the time of childbirth relatively well. When an analysis was conducted on only this group, the under $\$ 3000000$ group had a significantly lower RR value (RR, $0.898 ; 95 \% \mathrm{Cl}, 0.816$ to 0.916$)$ than the over $\forall 3000000$ group. This figure is lower than the $0.93 \mathrm{RR}$ value of the 40 to 50 age group, signifying that income can actually have a bigger influence on the number of children. Likewise, given the limitations of the data, there was no information about how many household members there were, so we were unable use the household income indicator to take into account this influence. For occupation, we used the job that the subject had worked the longest as well as their current job. Since more time had passed for older subjects since giving birth, the probability that they started their long-term occupation after giving birth was a problem. The current occupation, likewise, is problematic for explaining the situation at the time of giving birth, leading to the possibility of a bias emerging. In this study, there were 50 individuals without a long-term occupation for whom we substituted their current occupation. For $66 \%$ of the subjects, their current occupation was the same as their long-term occupation. We can guess that around 17 individuals incorrectly inputted their long-term occupation. Since occupation categories were changed fewer times than this, we judged that substituting the current occupation for the longterm occupation would not cause any significant problems. There was also a limitation in that we looked exclusively at women above 40 . There is a need for research looking into various other factors apart from the socioeconomic levels analyzed in this study. Solving the problem of multicollinearity by using models like principal component analysis could prove a means to overcoming this point of limitation. Particularly, in 
the case of household income, we observed that the greater the number of children the greater the income for 40 to 45 year-olds, whose income at the time of the survey was likely to have better reflected their income level at the time of childbirth than that of the other age groups. In light of this, we feel that if income at the time of childbirth was estimated and reflected in the study, we would be able to reach a clearer conclusion. For occupation as well, supplemental data is needed, such as asking about the subject's occupation at the time of childbirth. When looking at dependent variables as well, the absence of information about stillborn babies and miscarriages was another limitation. Future research will need to carry out analysis that reflects such information about miscarriage experience, not limiting variables to fertility and natality, but also examining change initiatives such as childbirth plans. Expanding research to include women of all ages would likewise be helpful. For the household equivalence scale, we used household income itself. This was because no supplemental study has been performed on whether the number of household members agrees with actual economic units, which, we deemed, could actually be more inaccurate. In the future, if we are able to obtain information about actual economic units, we will be able to use household income adjusted for the number of households [24]. Furthermore, rather than only analyzing women aged 40 and above, we could alternatively analyze the incomplete fertility rate by including younger women as subjects [19]. If that happens, the number of research subjects could be expanded and the power of the analysis increased. Finally, as for limitations in the case of smoking and alcohol history, while the never-consumers certainly did not smoke or drink during pregnancy, it is difficult to say whether present or past consumers did so during pregnancy. In the future, we should conduct a more detailed survey and supplement these findings.

Despite these limitations, this study's significance lies in having determined the influence of socioeconomic level on fertility and that there is a hereditary factor. In particular, considering the tendency for working women to have a smaller number of children than homemakers, and the influence of income on the number of children of the relatively young group of those in their 40s, there is a need to examine whether the current birth encouragement policy is taking working and low-income women into consideration.

\section{CONFLICT OF INTEREST}

The authors have no conflicts of interest with the material presented in this paper.

\section{REFERENCES}

1. Statistics Korea. 2010 Birth statistics (confirm); 2011 [cited 2013 Jan 16]. Available from: http://kosis.kr/abroad/abroad_ 01List.jsp (Korean).

2. Ahn JY. Long-term demand forecast (2005-2020). Mon Labor Rev 2005;(6):3-23 (Korean).

3. Becker GS, Duesenberry JS, Okun B. An economic analysis of fertility. In: Universities-National Bureau. Demographic and economic change in developed countries. Cambridge: UMI; 1960, p. 209-240.

4. Heckman JJ, Willis RJ. Estimation of a stochastic model of reproduction an econometnc approach. In: Terleckyj NE, editor. Household production and consumption. Cambridge: NBER; 1976, p. 99-146.

5. Becker GS, Lewis HG. Interaction between quantity and quality of children. In: Schultz TW, editor. Economics of the family: marriage, children, and human capital. Cambridge: UMI; 1974, p. 81-90.

6. Becker G, Tomes N. Child endowments, and the quantity and quality of children. J Polit Econ 1976;84(4):S143-S162.

7. Caudill SB, Mixon FG. Modeling household fertility decisions: estimation and testing of censored regression models for count data. Empir Econ 1995;20(2):183-196.

8. Gensler $\mathrm{H}$. Welfare and the family size decision of low-income, two-parent families. Appl Econ Lett 1997;4(10):607-610.

9. Davis NJ. Childless and single-childed women in early twentieth-century America. J Fam Issues 1982;3(4):431-458.

10. Park KS, Kim YH. Patterns of Korean women's life course. Korean J Popul Stud 2003;26(2):63-90 (Korean).

11. Ewer PA, Crimmins-Gardner E. Income in the income and fertility relationship. J Marriage Fam 1978;40(2):291-299.

12. Lee SS. Studies of causes of low fertility and comprehensive measures. Seoul: Presidential Committee on Ageing Society and Population Policy; 2005, p. 135-148 (Korean).

13. Kwon TH, Kim DS. Understanding of the population. Seoul: Seoul National University Press; 1990, p. 195-199 (Korean).

14. Sung J, Cho SI, Song YM, Lee K, Choi EY, Ha M, et al. Do we need more twin studies? The Healthy Twin Study, Korea. Int J Epidemiol 2006;35(2):488-490. 
15. Curtis KM, Savitz DA, Arbuckle TE. Effects of cigarette smoking, caffeine consumption, and alcohol intake on fecundability. Am J Epidemiol 1997;146(1):32-41.

16. Augood C, Duckitt K, Templeton AA. Smoking and female infertility: a systematic review and meta-analysis. Hum Reprod 1998;13(6):1532-1539.

17. Hakim RB, Gray RH, Zacur H. Alcohol and caffeine consumption and decreased fertility. Fertil Steril 1998;70(4):632-637.

18. Sung J, Cho SI, Lee K, Ha M, Choi EY, Choi JS, et al. Healthy Twin: a twin-family study of Korea: protocols and current status. Twin Res Hum Genet 2006;9(6):844-848.

19. Kim HS. The economic and social implication of count regression models for married women's completed fertility in Korea. Korean J Popul Stud 2007;30(3):107-135 (Korean).
20. McCulloch CE. Generalized linear mixed models. Ohio: Institute of Mathematical Statistics; 2003, p. 28-33.

21. Melkersson $M$, Rooth DO. Modeling female fertility using inflated count data models. J Popul Econ 2000;13(2):189-203.

22. Li C, Cao W, Yu J, Ke T, Lu G, Yang Y, et al. An instrument for in situ measuring the volume scattering function of water: design, calibration and primary experiments. Sensors (Basel) 2012;12(4):4514-4533.

23. Nelder JA, Wedderburn RW. Generalized linear models. J R Stat Soc A 1972;135(3):370-384.

24. Kim HR. Socioeconomic health inequalities and counter policies in Korea. Seoul: Korea Institute for Health and Social Affairs; 2004, p. 49-56 (Korean). 